\title{
A PRÁTICA DA TUTORIA NO PROJETO E-NOVA: UMA REFLEXÃO A PARTIR DOS CONCEITOS DE COMUNIDADE DE PRÁTICA
}

Andreza Regina Lopes da Silva | andrezalopes.ead@gmail.com

Mestranda do Programa de Pós-graduação em Engenharia e Gestão do Conhecimento da UFSC.

Isadora de Souza Bernardini | isa.bernardini@gmail.com

Mestranda do Programa de Pós-graduação em Administração da UFSC.

Jaqueline Rossato | inerossato@gmail.com

Doutoranda do Programa de Pós-graduação em Engenharia e Gestão do Conhecimento da UFSC.

Sabrina Rebelo | sabrinarebeloufsc@gmail.com

Mestranda do Programa de Pós-graduação em Engenharia e Gestão do Conhecimento da UFSC.

Fernando José Spanhol | fernando.s@unitins.br/spanhol@led.ufsc.br

Vice reitor da Universidade Estadual do Tocantins, Professor Permanente do Programa de Pos-graduação em Engenharia e Gestão do Conhecimento da UFSC, Doutor em Mídia e Conhecimento pela UFSC.

\section{Resumo}

O presente artigo tem como objetivo buscar evidências que possam ilustrar semelhanças entre a tutoria do projeto e-Nova e as comunidades de prática. Para tanto, a metodologia utilizada caracteriza a pesquisa como teórico-empírica, de natureza exploratória e descritiva; a sua abordagem classifica-se como qualitativa. A unidade de análise escolhida foi o curso de capacitação do e-Nova, projeto que tem como objetivo a disseminação do empreendedorismo inovador e a geração de produtos e processos inovadores com sucesso técnico e mercadológico. Como método, utilizou-se o estudo de caso, pois busca caracterizar o grupo de tutoria do projeto e identificar elementos que possam qualificá-lo como uma comunidade de prática. Como resultado, observa-se que a tutoria do projeto e-Nova possui três características basilares: trata-se de um grupo de trabalho intensivo em conhecimento; atua sobre um conjunto comum de questões; e promove a criação de novos conhecimentos por meio do compartilhamento. Conclui-se que, em sua maioria, as características desse grupo se assemelham a aspectos pertencentes a uma comunidade de prática, tais como: possui um grupo de indivíduos que se importa com um conjunto comum de questões e que compartilha e desenvolve conhecimentos nesse domínio.

\section{Palavras-chave}

Gestão do conhecimento. Comunidade de prática. Tutoria. 
The practice of tutoring in the

"e-Nova"Project: A reflection based on the concepts of community of practice.

\section{Abstract}

This article is aimed at seeking evidence to illustrate the similarity between the e-mentoring project and the new communities of practice. For this purpose, the methodology used to characterize the theoretical and empirical research, exploratory and descriptive, whereas their approach is classified as qualitative. The unit of analysis was the chosen course of new e-training project which aims at the dissemination of innovative entrepreneurship and the creation of innovative products and processes with technical and market success. As a method, we used the case study because it seeks to characterize the group mentoring project and identifying features that can characterize it with a community of practice. As a result, it is observed that the mentoring project and the new one has have three basic characteristics: it is They are a groups of knowledge-intensive work, they acts on a common set of issues, and they promotes the creation of new knowledge through share. We conclude that, in most cases, the characteristics of this group resemble aspects belonging to a community of practice, such as has a group of individuals who care about a common set of questions, and share and develop knowledge in this area.

\section{Keywords:}

Knowledge management. Community of practice. Mentoring.

\section{La práctica de la tutoría en el proyecto y el Nuevo: una reflexión sobre los conceptos de comunidad de práctica}

\section{Resumen}

Este artículo está dirigido a la búsqueda de pruebas para ilustrar la similitud entre el proyecto de e-mentoring y las nuevas comunidades de práctica. Para ello, la metodología utilizada para caracterizar la investigación teórica y empírica, exploratoria y descriptiva, mientras que su enfoque está clasificado como cualitativos. La unidad de análisis fue elegido como el curso de formación y el Nuevo, un proyecto que tiene como objetivo la difusión del espíritu empresarial innovador y la creación de productos y procesos innovadores con éxito técnico y de mercado. Como método, se utilizó el estudio de caso, ya que busca caracterizar el proyecto de tutoría en grupo y la identificación de las características que se puede caracterizar con una comunidad de práctica. Como resultado, se observa que el proyecto de tutoría y el Nuevo tiene tres características básicas: es un grupo de trabajo intensivas en conocimiento, actúa sobre un conjunto común de problemas, y promueve la creación de nuevos conocimientos a través de compartir. Llegamos a la conclusión de que, en la mayoría de los casos, las características de este grupo se asemejan a los aspectos que pertenecen a una comunidad de práctica, como la tiene un grupo de personas que se preocupan por un conjunto común de preguntas, y compartir y desarrollar conocimientos en esta área.

\section{Palabras clave:}

Gestión del conocimiento.

Comunidad de práctica. Tutoría.

\section{INTRODUÇÃO}

Na sociedade do conhecimento, as organizações desenvolvem a capacidade de criar conhecimentos em resposta ao surgimento das necessidades. De acordo com Nonaka e Takeuchi (1997), o conhecimento é criado por indivíduos, que podem ser apoiados e estimulados pela organização. Assim, uma instituição consegue ampliar e disseminar os conhecimentos criados por indivíduos, fixando-os como parte de sua rede de conhecimentos.

Sveiby (2003) destaca que os trabalhadores do conhecimento são os principais responsáveis pela criação de riqueza organizacional. O sucesso e a sobrevivência das organizações dependem do de- 
sempenho de seus colaboradores. Dessa forma, a única maneira de uma organização melhorar seu desempenho numa economia e sociedade baseadas em conhecimento é obter mais das mesmas pessoas, ou seja, é necessário gerenciar as competências da equipe a fim de conseguir maior produtividade.

Em meio a esse contexto estão inseridas as comunidades grupais, que, de maneira geral, são grupos de pessoas (trabalhadores do conhecimento) que se articulam para resolver problemas e potencializar o alcance dos resultados das organizações. Em contraponto a uma solução tecnológica, diversas comunidades têm sido desenvolvidas como um método de implementação social da gestão do conhecimento; entre elas estão as comunidades de prática (WENGER, 1998).

A unidade de análise desta pesquisa é um curso de extensão que tem o intuito de contribuir com a economia do conhecimento por meio da promoção, da atualização e do aperfeiçoamento de empreendedores e potenciais empreendedores de base tecnológica. O projeto foi idealizado em 2010 pelo Departamento de Engenharia e Gestão do Conhecimento da Universidade Federal de Santa Catarina (EGC/UFSC) e a Fundação CERTI (Centro de Referências em Tecnologias Inovadoras) e conta com o apoio do Conselho Nacional de Desenvolvimento Científico (CNPq), do $\mathrm{Mi}$ nistério da Ciência e Tecnologia (MCT), da Rede Catarinense de Entidades de Empreendimentos Tecnológicos (RECEPET) e da Rede Amazônica de Instituições em prol do Empreendedorismo e Inovação (RAMI).

Este artigo possui por meta buscar evidências que possam ilustrar semelhanças entre a tutoria do projeto e-Nova e as comunidades de prática (CoPs). Para a composição desse objetivo, foi colocado em perspectiva o estudo desenvolvido por Wenger e Snyder (2001), o qual apresenta e compara os diferentes grupos em suas principais características, assim como a apresentação da tutoria do projeto e-Nova.

Além desta introdução e das considerações fi- nais, este artigo apresenta cinco outros tópicos: o segundo destaca a gestão do conhecimento $e$ o conceito de comunidade de prática; o terceiro apresenta conceitos e características da tutoria na Educação a Distância; o quarto delimita as orientações metodológicas deste estudo; o quinto estabelece uma relação entre as características da tutoria do projeto e-Nova e os diferentes grupos apresentados por Wenger e Snyder (2001); por fim, são apresentadas as referências bibliográficas utilizadas para embasar o artigo.

\section{Gestão do conhecimento}

A gestão do conhecimento (GC) pode ser entendida como a ação ou prática relacionada aos processos de criação, disseminação e uso do conhecimento para atingir os objetivos da organização, conforme sugerem Skyrme e Amidon (1997) e Davenport e Prusak (1998).

São diversas as definições para o conceito de gestão do conhecimento, como já apontou Dalkir (2005), que, em uma pesquisa informal, identificou mais de 100 acepções publicadas para o termo. Com base na análise dos resultados obtidos na literatura, o referido autor identificou os quatro modelos basilares do ciclo de vida da GC - que são retratados por Meyer e Zack (1996), Bukowitz e Williams (2000), McElroy (2003) e Wiig (1993).

Tais modelos foram selecionados por apresentarem os principais processos de gestão do conhecimento; as três etapas principais e comuns citadas pelos autores mencionados são: a) captura: identificação e codificação e/ou criação de conhecimento; b) compartilhamento e disseminação do conhecimento; e c) aquisição e aplicação do conhecimento.

No modelo proposto por Meyer e Zack (1996), os principais processos de GC são: aquisição, refinamento, estocagem/recuperação, distribuição $e$ apresentação. Embora não descrita explicitamente nesse modelo, há também uma noção de renovação contínua e de aperfeiçoamento, o que, para a gestão do conhecimento, é crucial.

No modelo de Bukowitz e Williams (2000), o 
processo de GC é descrito como "a maneira de as organizações criarem, manterem e implantarem um estoque estrategicamente correto de conhecimento para gerar valor". A diferença, se comparado ao ciclo apontado por Meyer e Zack (1996), é que aquele apresenta dois novos processos: a aprendizagem e a decisão de manter e/ou ceder o conhecimento para a organização.

McElroy (2003) enfatiza que o conhecimento organizacional é realizado tanto na subjetividade das mentes dos indivíduos como de forma objetiva e explícita. Para o autor, a GC é mais do que criar espaços para armazenagem e posterior gerenciamento de documentos ou conhecimentos que foram armazenados. Trata-se, sim, de focalizar processos e identificar o conteúdo do conhecimento que é de valor para a organização e seus colaboradores.

No modelo de Wiig (1993), há quatro etapas importantes na gestão do conhecimento: a) criação; b) retenção; c) intercâmbio; e d) aplicação. Uma das vantagens da abordagem do ciclo de Wiig, se comparada às demais já apresentadas, é a clara e detalhada descrição de como a memória organizacional é colocada em uso a fim de gerar valor para os indivíduos, grupos e organizações.

Para fins deste trabalho, considera-se que gestão do conhecimento é a coordenação sistemática e deliberada de pessoas, tecnologias, processos $e$ estrutura organizacional, com o objetivo de agregar valor pela reutilização e pela inovação. Esta coordenação é alcançada por meio da criação, do compartilhamento e da aplicação do conhecimento, bem como pela alimentação das valiosas lições aprendidas e das melhores práticas para a memória corporativa voltada a promover a continuação da aprendizagem organizacional (DALKIR, 2005).

Para Nonaka e Takeuchi (1997), a gestão do conhecimento é a atividade de divulgar e explicitar os saberes implícitos nas práticas individuais e coletivas das organizações. Probst, Raub e Romhardt (2002, p. 30) complementam ao afirmar que "a gestão do conhecimento consiste em um conjunto integrado de intervenções que aproveitam as oportunidades para dar forma à base de conhecimento".

Cabe destacar que a gestão do conhecimento é, sobretudo, gestão de pessoas, o que permite afirmar que o conhecimento é uma prática compartilhada, indo ao encontro da definição de comunidade de prática, a qual, em prol de um objetivo, cria, usa, debate, distribui, adapta e transforma o conhecimento (DESPRES; CHAUVEL, 2000). Diferentes comunidades têm sido desenvolvidas como um método de implementação da gestão do conhecimento, dentre as quais Wenger (1998) aponta a comunidade de prática.

\section{Comunidades de prática}

Em 1991, Lave e Wenger, em sua obra Situated Learning, introduziram o termo comunidade de prática $(\mathrm{CoP})$, o qual foi definido como organização informal (grupo de pessoas) naturalmente formada entre praticantes de dentro e de fora das fronteiras de organizações formais. Nesse estudo, os autores chamaram a atenção para o fato de que o aprendizado e a comunicação ocorrem simultaneamente em termos da prática e da comunidade.

Apesar de a introdução do termo community of practice ter ocorrido na literatura somente em época recente, a existência de comunidades de prática não é algo novo, como alertam Wenger e Snyder (2001, p. 12):

as comunidades de prática já existiam na antiguidade. $\mathrm{Na}$ Grécia clássica, por exemplo, "corporações" de serralheiros, oleiros, pedreiros e outros artífices tinham objetivo social (os associados adoravam as mesmas divindades e comemoravam juntos os dias sagrados) e também função comercial (os associados treinavam aprendizes e disseminavam as inovações).

Ampliando a discussão, Wenger (1998) definiu comunidade de prática como sendo a formação de um grupo de pessoas que se importa com um conjunto comum de questões, motivo pelo qual compartilha e desenvolve conhecimentos, organizando uma competência crítica para o sucesso organizacional. Outra definição seria: grupo de 
pessoas informalmente ligado pelo conhecimento especializado, que é compartilhado pela paixão por uma iniciativa conjunta (WENGER; SNYDER, 2001).

Terra (2011) afirma que as CoPs são formadas por pessoas que estão interligadas informal e contextualmente.

Tais comunidades são movidas pelo interesse comum no aprendizado e na aplicação prática. As comunidades de prática bem desenvolvidas têm a sua própria linguagem, o que permite uma melhor comunicação e afirmação da identidade do núcleo de prática e dos indivíduos que dele participam.

A formação das comunidades está relacionada frequentemente ao surgimento de vínculo entre os indivíduos de trabalho dentro dos limites da organização (LESSER; EVEREST, 2001). No entanto, segundo esses autores, suas características não são temporárias, como aquelas, por exemplo, de times ou grupos de uma dada seção em um treinamento.

Wenger e Snyder (2001) destacam que as comunidades de prática diferem de outras formas de organização. Para tanto, apresentam algumas características específicas das CoPs que as distinguem dos demais grupos organizacionais. Tais características são apresentadas no Quadro 1.

\begin{tabular}{|c|c|c|c|c|}
\hline Grupo & Qual é o objetivo? & Quem participa? & $\begin{array}{l}\text { O que tem em } \\
\text { comum? }\end{array}$ & $\begin{array}{l}\text { Quanto } \\
\text { tempo dura? }\end{array}$ \\
\hline $\begin{array}{l}\text { Comunidade } \\
\text { de Prática }\end{array}$ & $\begin{array}{l}\text { Desenvolver as } \\
\text { competências dos } \\
\text { participantes; gerar e } \\
\text { trocar conhecimentos. }\end{array}$ & $\begin{array}{l}\text { Participantes que se } \\
\text { auto-selecionam (e } \\
\text { integrantes que avaliam } \\
\text { a adequabilidade do } \\
\text { associado pretendente). }\end{array}$ & $\begin{array}{l}\text { Paixão, } \\
\text { compromisso e } \\
\text { identificação com } \\
\text { os conhecimentos } \\
\text { especializados do } \\
\text { grupo. }\end{array}$ & $\begin{array}{l}\text { Enquanto } \\
\text { houver interesse } \\
\text { em manter o } \\
\text { grupo. }\end{array}$ \\
\hline $\begin{array}{l}\text { Grupo de } \\
\text { trabalho } \\
\text { formal }\end{array}$ & $\begin{array}{l}\text { Desenvolver um } \\
\text { produto ou prestar um } \\
\text { serviço. }\end{array}$ & $\begin{array}{l}\text { Qualquer um que se } \\
\text { apresente ao gerente do } \\
\text { grupo. }\end{array}$ & $\begin{array}{l}\text { Requisitos do } \\
\text { trabalho e metas } \\
\text { comuns. }\end{array}$ & $\begin{array}{l}\text { Até a próxima } \\
\text { reorganização. }\end{array}$ \\
\hline $\begin{array}{l}\text { Equipe de } \\
\text { projeto }\end{array}$ & $\begin{array}{l}\text { Realizar determinada } \\
\text { tarefa. }\end{array}$ & $\begin{array}{l}\text { Empregados escolhidos } \\
\text { por gerentes seniores. }\end{array}$ & $\begin{array}{l}\text { As metas e pontos } \\
\text { importantes do } \\
\text { projeto. }\end{array}$ & $\begin{array}{l}\text { Até o final do } \\
\text { projeto. }\end{array}$ \\
\hline Rede informal & $\begin{array}{l}\text { Colher e transmitir } \\
\text { informações } \\
\text { empresariais. }\end{array}$ & $\begin{array}{l}\text { Amigos e conhecidos } \\
\text { do meio empresarial. }\end{array}$ & $\begin{array}{l}\text { Necessidades } \\
\text { mutuas. }\end{array}$ & $\begin{array}{l}\text { Enquanto as } \\
\text { pessoas tiverem } \\
\text { um motivo para } \\
\text { manter contato. }\end{array}$ \\
\hline
\end{tabular}

Com base no Quadro 1, percebe-se que os fatores que diferenciam as comunidades de prática dos grupos de trabalho formal, das equipes de projeto e das redes informais dizem respeito aos seus objetivos, aos seus integrantes, ao que os membros têm em comum e à duração dessas comunidades/grupos/equipes/redes.

Destaque-se que as comunidades de prática possuem por escopo desenvolver as competências de seus membros e proporcionar a geração $e$ disseminação do conhecimento, algo importante para a implementação da gestão do conhecimento. Além disso, trazem como característica a autosseleção dos participantes, ou seja, os próprios integrantes avaliam a adequabilidade do pretendente a associado. Cabe ressaltar que, segundo Terra (2011), a participação na CoP é voluntária.

Dessa forma, também seus integrantes participam da CoP por se identificar com a comunidade, no sentido de que são movidos pela paixão pelos conhecimentos do grupo. Assim, igualmente, as comunidades de prática existem enquanto os membros tiverem interesse de as integrar, isto é, a partir do momento em que esse interesse é minimizado, a paixão também é diminuída, o que gera o desmembramento da comunidade ou até mesmo sua extinção. 
Além das características supracitadas, apontam-se três outras fundamentais à caracterização de uma CoP (WENGER; SNYDER, 2001; WENGER, 1998; WENGER; MCDERMOTT; SNYDER, 2002):

- Domínio: área do conhecimento que integra o grupo, dando identidade e permitindo o direcionamento das questões-chave aos seus membros. Implica competência partilhada, que distingue os membros de outras pessoas;

- Comunidade: grupo de indivíduos para qual o domínio, a qualidade das relações e a definição de limites internos e externos são relevantes. $\mathrm{Ou}$ seja, a comunidade é formada por indivíduos que trocam informações, pensam e interagem uns com os outros. Os membros engajam-se em atividades conjuntas e, nas discussões, ajudam-se, havendo assim compartilhamento de informações. Eles constroem relações que lhes permitem aprender mutuamente;

- Prática: conjunto de métodos, de ferramentas e de documentos criados e compartilhados entre si que permite trabalhar de forma comum com o problema do domínio que precisa ser resolvido. Membros de uma comunidade de prática são praticantes e desenvolvem um repertório compartilhado de recursos: experiências, histórias, ferramentas, formas de abordar problemas recorrentes de uma prática compartilhada etc. Isso leva tempo e interação sustentada. O desenvolvimento de uma prática compartilhada pode ser mais ou menos autoconsciente. Por exemplo, os enfermeiros que se encontram regularmente para almoçar no restaurante do hospital podem não perceber que as discussões do almoço são uma das suas principais fontes de conhecimento sobre como cuidar de pacientes. Ainda assim, no decorrer de todas essas conversas, eles recolheram um conjunto de histórias e de casos que se tornou um repertório compartilhado para sua prática.

Sendo assim, uma comunidade de prática possui uma identidade própria definida por interesses comuns às pessoas envolvidas, o que a diferencia dos demais tipos de grupos. Percebe-se que a combinação dessas características que definem a
CoP pode também contribuir para a gestão do conhecimento, uma vez que o conhecimento é uma prática compartilhada que, em prol de um objetivo, cria, usa, debate, distribui, adapta e transforma o conhecimento (DESPRES; CHAUVEL, 2000).

\section{Tutoria na Educação a Distância}

A ideia central da educação a distância (EAD) é simples: alunos e professores estão em locais diferentes durante toda ou boa parte do tempo em que aprendem e ensinam. Por se encontrarem em locais distintos, dependem de algum tipo de tecnologia voltada a transmitir informações de forma a proporcionar-lhes um meio para interagir (MOORE; KEARSLEY, 2007).

Estudar a distância ocasiona inúmeras mudanças, não somente para o estudante, mas também para o professor e a instituição de ensino. Assim, torna-se necessário trabalhar a fim de que a oferta de cursos a distância não seja prejudicada pelas deficiências de atendimento. Nesse sentido, a tutoria surge como peça-chave na ação de aprendizagem (DALMAU, 2009).

A tutoria, como método, nasceu no século XV, na universidade, sendo utilizada para a orientação de caráter religioso aos alunos. No século XX, o tutor passou a assumir o papel de orientador e acompanhante dos trabalhos acadêmicos, e é com esse mesmo sentido que se incorporou aos atuais programas de educação a distância (SÁ, apud MACHADO; MACHADO, 2004). Ampliando a discussão, pode-se afirmar que, a partir do surgimento e disseminação da internet, em meados da década de 1990, o papel do tutor se consolidou, passando a ser essencial ao processo de aprendizagem do aluno (INED, 2003; MARTINS; SPANHOL, 2006).

Mill (2007) diferencia a tutoria presencial da tutoria a distância: a primeira é composta por um grupo de educadores que acompanha, presencialmente, os estudantes alunos, por meio de encontros que podem ser frequentes ou esporádicos; a outra consiste no acompanhamento dos alunos a 
distância, mediante o uso de tecnologias de informação e comunicação.

O tutor a distância deve acompanhar o aluno ao longo do curso; cabe a ele a tarefa de avaliar o estudante, bem como orientá-lo e motivá-lo. Para Dalmau (2009), o tutor é a pessoa responsável por fazer todo o acompanhamento do participante ao longo do curso, criando condições mínimas com o propósito de que o estudante a distância não sinta tanta diferença em relação ao modo presencial.

Algumas qualidades são fundamentais para um tutor. Segundo Aretio (2002), são: autenticidade e honestidade; maturidade emocional; bom caráter e cordialidade; compreensão de si mesmo; capacidade empática; inteligência e agilidade mental; capacidade de escutar; cultura social; estabilidade emocional; capacidade de aceitação; inquietude cultural e amplos interesses; e liderança.

Cada uma dessas qualidades varia de acordo com o indivíduo. No entanto, é importante destacar que o aluno vê na presença do tutor um auxiliador que estará sempre disponível.

Assim, para desenvolver uma boa relação com o estudante, o tutor precisa possuir algumas das características aqui mencionadas.

Tais características são importantes para a realização das principais atividades do tutor, das quais Aretio (2002) destaca:

- Acompanhar o desempenho do estudante durante as atividades;

- Auxiliar e orientar os estudantes nos estudos procura sanar todas as possíveis dúvidas;

- Estimular o estudante a buscar informações complementares;

- Motivar o estudante; e

- Ter domínio do conteúdo do curso.

É cada vez mais evidente a importância da tutoria para a modalidade Educação a Distância. Quanto mais os tutores se empenharem para auxiliar os alunos de forma satisfatória, melhor tende a ser o processo de ensino-aprendizagem na educação baseada no método a distância, como sugere a figura 1.

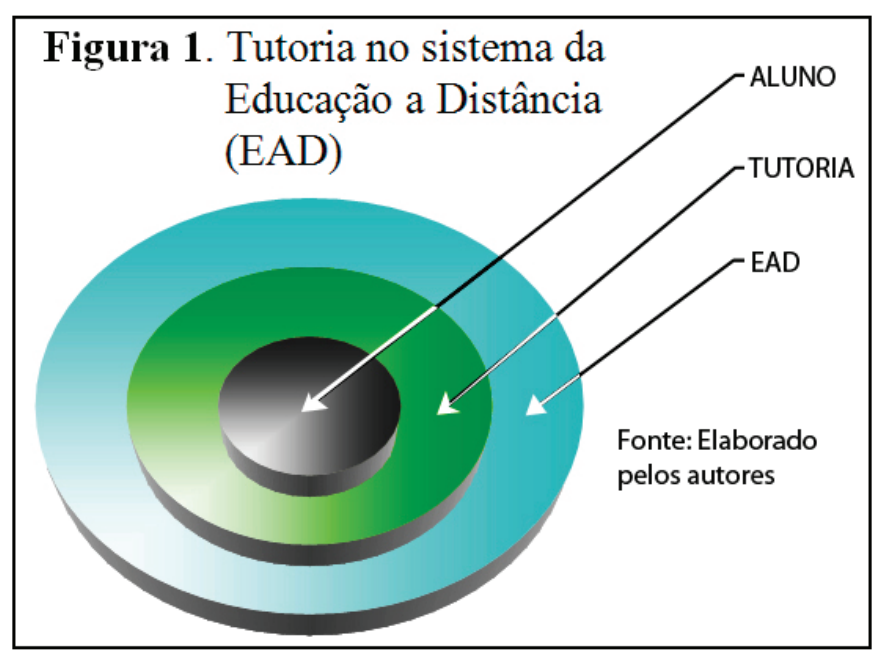

Nesta perspectiva, pode-se afirmar que um sistema de tutoria nas instituições que oferecem educação a distância de qualidade deve prever a atuação de tutores que tenham por principal objetivo o acompanhamento e a mediação do aluno, a fim de esclarecer as dúvidas por meio das diferentes ferramentas de EAD (síncronas ou assíncronas), de acordo com o projeto pedagógico (BRASIL, 2007).

De forma descritiva, Mill (2010) afirma que o tutor a distância (virtual) é responsável por acompanhar os alunos em seus estudos, contribuindo, por meio de orientações, com seu aprendizado. $\mathrm{O}$ autor destaca ainda que, diante da elevada quantidade de estudantes matriculados em uma disciplina, o tutor pode complementar sua tarefa didática mediante, por exemplo, uso de grupos e listas de discussão, fóruns, chats e de outros meios de comunicação.

Silva et al (2010) apontam que o termo tutor está diretamente relacionado ao termo "ensino", com a especificidade de promover uma aprendizagem mais especializada, isto é, mais específica para os tutoriados. Sendo assim, pode-se afirmar que a tutoria é, em especial, uma comunidade de EAD que busca balizar os objetivos de aprendizagem, corroborando significativamente a efetivação do curso em todos os níveis.

Com esse avanço, a EAD tende a tornar-se cada vez mais um elemento regular e necessário aos sistemas educativos, não somente com a finalida- 
de de atender demandas específicas, mas também para se estabelecer como função de grande relevância, especialmente na educação da população adulta, pela demanda crescente dos cursos supletivos, de formação continuada e de pós-graduação (VIANNEY; BARCIA; LUZ, 2006).

Cabe ressaltar que, apesar da importância do papel do tutor para a EAD, ainda inexiste diploma legal que regulamente seus direitos e deveres como profissional. Nesse sentido, Neves e Fidalgo (2008, p. 6) relatam que: "na legislação não há alusão sobre a regulamentação da profissão de tutor; portanto, não há garantias no que se refere ao processo de profissionalização desses também docentes".

Em complemento, Mill, Sales e Santiago (apud Barros, 2007) destacam que, quando existem, geralmente os contratos de trabalho são temporários, vagos e pagos na forma de bolsa, sendo os ganhos salariais considerados, em média, baixos. Dada a figura de destaque do tutor no processo educacional a distância, tornam-se essenciais, por consequência, melhorias no que concerne à regulamentação do seu trabalho, incluindo: forma de remuneração, direitos autorais e número de alunos por tutor.

\section{Orientações metodológicas}

Para alcançar o objetivo proposto, a pesquisa adotou o delineamento sugerido por Vergara (2003): a) quanto aos fins, a pesquisa tem natureza exploratória e descritiva; e b) relativo aos meios, trata-se de uma pesquisa bibliográfica.

Exploratória porque, embora as comunidades de prática sejam um tema de grande relevância, os estudos que abordam esse fenômeno envolvendo a prática da tutoria são ainda escassos. $\mathrm{O}$ estudo é descritivo, visto que busca identificar, descrever e analisar as características da comunidade de prática e a tutoria no projeto e-Nova.

Quanto aos meios, cuida-se de uma pesquisa bibliográfica, por ser um estudo sistematizado desenvolvido com base em material publicado e que, segundo Jung (2004, p. 160), objetiva "conhecer as diversas formas de contribuições científicas existentes que foram realizadas sobre determinado assunto ou fenômeno". A busca à literatura foi realizada em meios diversos, tais como em bases de dados multidisciplinares, consulta a livros, a periódicos, a relatórios técnicos, a teses, a dissertações e a anais de eventos.

A respeito da classificação, ele se enquadra como estudo de caso que, conforme Trivinos (1992, p. 133), é definido como "uma categoria de pesquisa cujo objeto é uma unidade que se analisa profundamente".

A coleta dos dados foi realizada pela observação participante, que consiste na técnica em que o pesquisador está desempenhando um papel participante estabelecido no local de estudo, ou seja, em uma situação de pesquisa em que o observador e observado se encontram face a face (SERVA; JÚNIOR, 1995). A coleta foi possível por meio dessa técnica, tendo em vista que um dos autores do artigo desempenha atividades na tutoria investigada.

Os dados foram tratados qualitativamente, com a tentativa de traçar uma abordagem interpretativa, isto é, a análise foi feita para identificar e caracterizar o tema, o que permitiu uma interpretação que propiciou conclusões sobre seu significado e, assim, sugeriu mais perguntas a serem feitas. Nessa perspectiva de análise, consoante Creswell (2007), o pesquisador possui a função de filtrar os dados por meio de uma lente pessoal.

\section{Análise do caso: \\ a prática da tutoria no projeto e-Nova}

O projeto e-Nova, também denominado programa de Capacitação em Rede: Competências para o Ciclo de Desenvolvimento de Inovações, é promovido pelo Departamento de Engenharia e Gestão do Conhecimento da Universidade Federal de Santa Catarina (EGC/UFSC) e pela Fundação CERTI (Centro de Referências em Tecnologias Inovadoras), com o apoio do Conselho Nacional de Desenvolvimento Científico (CNPq), do Ministério da Ciência e Tecnologia (MCT), da Rede 
Catarinense de Entidades de Empreendimentos Tecnológicos (RECEPET) e da Rede Amazônica de Instituições em prol do Empreendedorismo e Inovação (RAMI).

Seu objetivo é a disseminação do empreendedorismo inovador $e$ a geração de produtos $e$ processos inovadores com sucesso técnico e mercadológico. Conta com uma equipe de conteudistas, mestres e doutores com grande experiência em gestão de projetos de inovação. Com duração prevista para dez meses, o curso é oferecido gratuitamente a empreendedores e potenciais empreendedores de base tecnológica e está organizado em cinco módulos, sendo um introdutório e quatro específicos, totalizando 184 horas de aula.

O planejamento do curso teve início em 2010, consolidando sua turma piloto em fevereiro de 2011, com um total de 750 alunos. O curso é oferecido na modalidade a distância, permitindo aos alunos flexibilidade de tempo e espaço, e conta com o uso de diversos materiais: livro-texto, videoaula, atividades de aprendizagem e jogos, bem como fórum de discussão, fórum networking e fórum voltado ao compartilhamento de materiais, disponíveis de modo assíncrono.

O conteúdo fornece mecanismos destinados ao desenvolvimento de competências nas capacitações que compõem o programa: gestão da inovação; financiamento da inovação; análise da viabilidade da inovação; e desenvolvimento da inovação. As quatro áreas, que são independentes e complementares, abordam os principais conhecimentos necessários aos empreendedores no contexto do ciclo. Para cada capacitação, o aluno recebe um certificado emitido pela Universidade Federal de Santa Catarina (UFSC).

O curso é apoiado por um sistema de tutoria constituído por cinco tutores e um coordenador de tutoria, todos com formação superior em nível de mestrado e doutorado, pertencentes ao Programa de Pós-Graduação em Engenharia e Gestão do Conhecimento, que tem por objetivo acompanhar e assessorar o aluno em questões técnicas de acesso ao ambiente virtual de aprendizagem
(AVA), bem como acompanhar os tutorados sob a perspectiva didático-pedagógica, primando pela qualidade do processo de aprendizagem. O interesse comum na tutoria do projeto e-Nova está na capacitação e no auxílio ao processo de ensino-aprendizagem dos alunos.

Com a finalidade de atender de forma qualitativa aos estudantes, a equipe de tutoria faz uso do livro-texto e da videoaula, com a explicitação do conhecimento em grupo (socialização), oportunizando, desse modo, o desenvolvimento da competência nessa comunidade, a qual tem como escopo principal auxiliar o aluno na modelagem do conhecimento em relação aos aspectos de empreendedorismo inovador. A interação entre o grupo (tutores e coordenador) por meio de linguagem clara e a informação durante o contato presencial e virtual, pelo uso de e-mail e MSN, também contribuem neste processo. É importante salientar que o conhecimento explicitado pela coordenação do curso mediante reuniões com tutores e coordenação de tutoria beneficia os tutores nas suas atividades, tanto em termos de conteúdo quanto de projeto do curso.

É válido destacar que os tutores, assim como a coordenação do sistema, foram predefinidos por uma seleção e encontram-se em regime de contratação por um período previsto de 12 meses, a fim de atender todo o curso, fazer o fechamento da avaliação e os relatórios no momento de finalização. As pessoas envolvidas nesse processo têm em comum a paixão e o compromisso pela qualidade da educação, assim como o entendimento de que, para constituir uma sociedade do conhecimento, é indispensável uma base de formação continuada. Vale mencionar que todos os envolvidos no projeto e-Nova, especialmente os alunos de mestrado e doutorado, possuem, como base de suas pesquisas e projetos de dissertação e tese, temas relacionados à Educação a Distância e buscam atuar profissionalmente em projetos atrelados a essa área.

O grupo de tutores e o curso devem concluir suas atividades em dezembro de 2011. Contudo, 
a partir da autosseleção entre os membros, identificou-se que foram geradas relações duradouras que vão além do objetivo do projeto e-Nova, o que permite afirmar, na esteira dos conceitos expostos, a identificação do grupo com uma comunidade de prática.

Portanto, diante dos elementos apresentados em relação à tutoria do projeto e-Nova, é possível estabelecer ligações entre as características da tutoria e aquelas dos grupos destacadas por Wenger e Snyder (2001) apresentadas no Quadro 1.
Inicialmente, torna-se necessário elencar como será respondido cada um dos questionamentos propostos pelos autores no mencionado quadro, quais sejam: (a) qual é o objetivo?; (b) quem participa?; (c) o que tem em comum?; (d) quanto tempo dura?

Dessa forma, em paralelo ao quadro apresentado anteriormente, buscou-se evidenciar, no Quadro 2 , cada um desses questionamentos de acordo com a realidade da tutoria do projeto e-Nova.

Quadro 2: Características da tutoria do projeto e-Nova

\begin{tabular}{|c|c|c|c|c|}
\hline & Qual é o objetivo? & Quem participa? & $\begin{array}{l}\text { O que tem em } \\
\text { comum? }\end{array}$ & $\begin{array}{l}\text { Quanto tempo } \\
\text { dura? }\end{array}$ \\
\hline $\begin{array}{l}\text { Tutoria } \\
\text { do projeto } \\
\text { e-Nova }\end{array}$ & $\begin{array}{l}\text { Capacitar e auxiliar os } \\
\text { alunos no processo de } \\
\text { ensino/aprendizagem. } \\
\text { Existe, também, a } \\
\text { busca interna (entre } \\
\text { tutores e coordenador) } \\
\text { e externa (entre tutores } \\
\text { e alunos) de criação e } \\
\text { disseminação de } \\
\text { conhecimentos. }\end{array}$ & $\begin{array}{l}\text { Os participantes da } \\
\text { tutoria são escolhidos } \\
\text { por meio de processo } \\
\text { seletivo, no entanto, } \\
\text { observa-se também, } \\
\text { que a proximidade } \\
\text { diária proporciona } \\
\text { uma seleção natural } \\
\text { entre os membros. }\end{array}$ & $\begin{array}{l}\text { Todos os } \\
\text { participantes são } \\
\text { mestrandos e } \\
\text { doutorandos com } \\
\text { atividade de } \\
\text { pesquisa } \\
\text { relacionada a } \\
\text { Educação a } \\
\text { Distância. }\end{array}$ & $\begin{array}{l}\text { Em regime de } \\
\text { contratação por um } \\
\text { período de } 12 \\
\text { meses. Entretanto, } \\
\text { as relações tendem } \\
\text { a ser mais } \\
\text { duradouras, } \\
\text { ultrapassando os } \\
\text { limites de } \\
\text { finalização do } \\
\text { projeto. }\end{array}$ \\
\hline
\end{tabular}

Fonte: Elaborado pelos autores

Quando se atenta para o objetivo do projeto e-Nova, conforme apresentado no Quadro 2, a prática da tutoria mais se assemelha à caracterização de equipe de projetos anteriormente apresentada por Wenger e Snyder (2001), pois se trata da reunião de um grupo de pessoas capacitadas a fim de realizar determinada tarefa - no caso, capacitar e auxiliar os alunos no processo de ensino-aprendizagem. Além desse aspecto, a tutoria escolhe seus participantes por meio de um processo seletivo, todos contratados com o intuito de realizar determinada atividade. Tal característica é semelhante ao que pode ser encontrado nas equipes de projeto.

No que tange às relações em comum entre os participantes do projeto (os tutores), existem semelhanças com vários tipos de grupos apresentados por Wenger e Snyder (2001). É que todos os participantes são mestrandos e doutorandos com atividades de pesquisa voltadas à Educação a Distância, ou seja, apresentam identificação com os conhecimentos especializados, uma característica da CoP, além de possuírem metas comuns, uma qualidade de grupos de trabalhos formais $e$ equipe de projetos.

Em se tratando do tempo de duração da tutoria do projeto e-Nova, que é de 12 meses, este grupo mais se assemelha a grupos de trabalho formais $e$ equipes de projeto, pois permanece atuando até o termino do projeto vigente e a próxima reorganização de oferta do projeto.

Assim, percebe-se que a tutoria do projeto $e$ -Nova apresenta características de mais de um dos grupos citados por Wenger e Snyder (2001). De modo geral, pode-se constatar que a tutoria do projeto e-Nova, em sua constituição formal, apresenta relação com as equipes de projeto, tendo em vista que é responsável por realizar uma tarefa (capacitação de empreendedores ou potenciais empreendedores), seus participantes são escolhidos por meio processo seletivo e a sua duração é limitada até o fim do projeto. 
Apesar de apresentar características de equipes de projeto, a tutoria do projeto e-Nova, se observada mais profundamente - indo além das relações formais -, apresenta contornos de uma comunidade de prática. Pode-se destacar que os atores da tutoria buscam trocar e gerar conhecimentos relacionados à prática de tutoria, bem como sobre Educação a Distância. Afora isso, a proximidade diária e os interesses em comum estimulam a permanência dos elementos que têm objetivos voltados para a EAD.

$\mathrm{Na}$ tutoria do projeto e-Nova, observa-se que os integrantes possuem em comum a paixão pela qualidade da EAD. Desse modo, muito embora tenha tempo limitado, no sentido de uma equipe de projeto, a tutoria do projeto e-Nova tende a ter duração mais estendida, em virtude da proximidade entre as pessoas envolvidas no projeto, das trocas de conhecimento e do compartilhamento de uma paixão em comum, o ensino.

Diante dos dados apresentados, verificou-se que a tutoria do projeto e-Nova compartilha conhecimento entre seus membros, que dispõem de um interesse comum e de um mesmo objetivo profissional: a organização e o sucesso do projeto. As práticas desse grupo baseiam-se no objetivo de fazer uma mediação entre o conteúdo, a instituição e o estudante. É possível traçar um paralelo com o pensamento de Wenger (1998), que caracteriza comunidade de prática como um grupo de pessoas que se importa com um conjunto comum de questões, compartilhando e desenvolvendo conhecimentos nesse domínio. Os tutores, nesse processo, são os trabalhadores do conhecimento que contribuem para a riqueza do curso. São os mediadores do conhecimento que, mediante práticas não formais, buscam a construção do conhecimento nesse domínio, apresentando, deste modo, qualidades que caracterizam "em parte" uma comunidade de prática.

\section{Considerações finais}

Com o objetivo de buscar evidências que pudessem ilustrar semelhanças entre a tutoria do projeto
e-Nova e as comunidades de prática, utilizou-se o estudo desenvolvido por Wenger e Snyder (2001), que apresenta e compara os diferentes grupos em suas principais características, e a apresentação da tutoria do projeto e-Nova.

Diante das constatações teóricas e empíricas, ficaram evidentes alguns aspectos, como, por exemplo, o fato de que a tutoria do projeto em análise é um grupo de trabalhadores do conhecimento que atua com um conjunto comum de questões e que promove a criação de novos conhecimentos por meio do compartilhamento.

Também foi possível perceber que esse grupo de tutoria apresenta características pertencentes a mais de um dos grupos citados por Wenger $e$ Snyder (2001). Em sua maioria, as características desse grupo assemelham-se a grupos formais de trabalho e equipes de projetos. Entretanto, extrapolando as características meramente formais, constatou-se que o grupo se aproxima do conceito de uma CoP, pois as pessoas que lá atuam se importam com um conjunto comum de questões e, para tanto, compartilham e desenvolvem conhecimentos nesse domínio.

Como arremate, sabe-se que os resultados apresentados por este artigo não podem ser generalizados, característica própria dos estudos de caso, por se tratar de uma ocorrência específica em uma tutoria. Portanto, a principal indicação de continuidade desta pesquisa refere-se à necessidade de outros grupos serem escolhidos para análise, a fim de que possam ser examinados pelo mesmo viés e, desse modo, buscar evidências que permitam caracterizá-los como comunidades de prática. Tal constatação, se afirmativa for, pode ser útil às equipes de tutoria, visto que, ao se identificarem como uma comunidade de prática, uma ferramenta da gestão do conhecimento, podem utilizar os métodos e técnicas para o seu gerenciamento e administração - quiçá potencializar a criação, o uso e a disseminação do conhecimento entre indivíduos de uma tutoria ou mesmo de tutorias externas. 


\section{Referências}

ARETIO, Lorenzo Garcia. La Educación a Distancia: de la teoria a la práctica. Barcelona: Ariel, 2002.

BARROS, V. A. O trabalho do docente virtual: análise jurídica das condições de trabalho decorrentes do sistema de educação a distância. In: XVI Congresso Nacional do Conpedi, 2008. Belo Horizonte. Anais do XVI Congresso Nacional do CONPEDI. Florianópolis: Fundação Boiteux, 2007. Disponível em: <http://www.conpedi.org.br/manaus/arquivos/anais/bh/veronica_altef_barros.pdf> Acesso em: 17 jan. 2012.

BRASIL, Ministério da Educação. Referenciais de qualidade para educação superior a distância. Secretaria de Educação a Distância, Brasília: 2007.

BUKOWITZ, W.; WILLIAMS, R. The knowledge management fieldbook. London: Prentice Hall, 2000. CRESWELL, J. W. Projeto de pesquisa: métodos qualitativo, quantitativo e misto. $2^{\mathrm{a}}$ ed. Porto Alegre: Artmed, 2007.

DALKIR, Kimiz. Knowledge Management in Theory and Practice. Boston: Elsevier, 2005.

DALMAU, Marcos Baptista Lopez. Introdução à Educação a Distância. $2^{a}$ ed. Florianópolis: Departamento de Ciências Administração - UFSC, 2009.

DAVENPORT, T. H.; PRUSAK, L. Working knowledge: how organizations manage what they know. Boston: Harvard Business School Press, 1998.

DESPRES, C.; CHAUVEL, D. Knowledge Horizons. London: Butterworth Heinemann, 2000.

INED - Instituto Nacional de Educação a Distância. Tutoria no EAD: um manual para tutores. Vancouver: Commonwealth of Learning, 2003.

JUNG, C. F. Metodologia para pesquisa e desenvolvimento: aplicada a novas tecnologias, produtos e processos. Rio de Janeiro: Axcel Books, 2004.

LAVE, J.; WENGER, E. Situated learning: legitimate peripheral participation Cambridge: Cambridge University Express, 1991.

LESSER, E.; EVEREST, K. Using communities of practice to manage intellectual capital. Ivey Business Journal. London, v. 65, n. 4, p. 37-41, 2001.

MACHADO, Liliana Dias; MACHADO, Elian de Castro. O papel da tutoria em ambientes de EAD, 2004. Disponível em: http://www.abed.org.br/congresso2004/por/htm/022-TC-A2.htm. Acesso em: 17 jan. 2012.

McELROY, M. The new knowledge management: complexity, learning and sustainable innovation. Boston: Butterworth-Heinemann, 2003.

MEYER, M.; ZACK, M. The design and implementation of information products. Sloan Management Review, v. 37, n. 3, p. 43-59, 1996.

MILL, Daniel. et al. O desafio de uma interação de qualidade na Educação a Distância: o tutor e sua importância nesse processo. 2008. Disponível em: http://www.cadernosdapedagogia.ufscar.br/index. php/cp/article/viewFile/106/63. Acesso em: 22 jan. 2012.

MILL, Daniel. Sobre o conceito de polidocência ou sobre a natureza do processo de trabalho pedagógico na Educação a Distância. In: MILL, Daniel; RIBEIRO, L. R. C; OLIVEIRA, M. R. G. (Orgs.). Polidocência na educação a distância: múltiplos enfoques. São Carlos: EdUFSCar, 2010.

MOORE, Michael; KEARSLEY, Greg. Educação a distância: uma visão integrada. São Paulo: Thomson Learning, 2007.

NEVES, Viana de Salles Inajara; FIDALGO, Fernando Selmar. Docente virtual na Educação a Distân- 
cia: condições de trabalho na rede privada de ensino, 2008. Disponível em: http://www.senept.cefetmg. br/galerias/Arquivos_senept/anais/quarta_tema3/QuartaTema3Artigo7.pdf. Acesso em: 18 jan. 2012. NONAKA, Ikujiro; TAKEUCHI, Hirotaka. Criação de conhecimento na empresa: como as empresas japonesas geram a dinâmica da inovação. $2^{a}$ ed. Rio de Janeiro: Campus, 1997.

PROBST, Gilbert; RAUB, Steffen; ROMHARDT, Kai. Gestão do conhecimento: os elementos construtivos do sucesso. Porto Alegre: Bookman, 2002.

SERVA, M.; JAIME Jr., P. Observação participante e pesquisa em administração: uma postura antropológica. Revista de Administração de Empresas, São Paulo, v. 35, n. 1, p. 64-79, mai/jun 1995.

SILVA, Andreza R. Lopes da et al. A terminologia da EAD: conceito e compreensão. In: CONGRESSO INTERNACIONAL DE EDUCAÇÃO A DISTÂNCIA. Anais do Congresso Internacional de Educação a Distância. Foz do Iguaçu: ABED, 2010a, 16, CD.

SKYRME, David; AMIDON, Debra. The Knowledge Agenda. The Journal of Knowledge Management, v. 1, n. 1, september, 1997.

SVEIBY, Karl Erick. A nova riqueza das organizações: gerenciando e avaliando patrimônios de conhecimento. $7^{\text {a }}$ ed. Rio de Janeiro: Campus, 2003.

TERRA, José Cláudio C. Comunidades de prática: conceitos, resultados e métodos de gestão. Biblioteca Terra Fórum Consultores. Disponível em: http://www.terraforum.com.br/biblioteca/Documents/ libdoc00000098v002Comunidades\%20de\%20Pratica-conceitos,\%20resultad.pdf. Acesso em: 3 jun. 2011.

TRIVINOS, Augusto N. S. Introdução à pesquisa em Ciências Sociais: a pesquisa qualitativa em Educação. São Paulo, Atlas, 1992.

VERGARA, Sylvia C. Projetos e relatórios de pesquisa em Administração. São Paulo: Atlas, 2003.

VIANNEY, João; BARCIA, Ricardo Miranda; LUZ, Rodolfo Joaquim Pinto da. Universidade virtual: oportunidade de crescimento ou ameaça para as instituições de ensino superior? Revista Estudos, n. 26, 2006. Disponível em: http:/www.abmes.org.br/abmes/public/arquivos/publicacoes/Estudos26.pdf. Acesso em: 18 jan. 2012.

WENGER, Etienne. Communities of practice: learning, meaning, and identity. 1998. Disponível em: http://bit.ly/iJRaly. Acesso em: 3 jun. 2011.

WENGER, Etienne; MCDERMOTT, Richard; SNYDER, William. Cultivating Communities of Practice: a guide to managing knowledge. Boston: Harvard Business School Press, 2002.

WENGER, Etienne; SNYDER, Willian. Comunidades de prática: a fronteira organizacional. In: Vários autores. Aprendizagem Organizacional. Tradução de Cássia Maria Nasser. Rio de Janeiro: Campus, 2001, p. 9-26.

WIIG, K. Knowledge management foundations. Arlington: Schema Press. 1993. 